ARTICLE

Received 1 May 2015 | Accepted 29 May 2015 | Published 9 Jul $2015 \quad$ DOl: 10.1038/ncomms8688

\title{
Inhibition of Ebola virus glycoprotein-mediated cytotoxicity by targeting its transmembrane domain and cholesterol
}

Moritz Hacke ${ }^{1}$, Patrik Björkholm² ${ }^{2}$ Andrea Hellwig ${ }^{3}$, Patricia Himmels ${ }^{1}$, Carmen Ruiz de Almodóvar ${ }^{1}$, Britta Brügger ${ }^{1}$, Felix Wieland ${ }^{1} \&$ Andreas M. Ernst ${ }^{1}$

The high pathogenicity of the Ebola virus reflects multiple concurrent processes on infection. Among other important determinants, Ebola fusogenic glycoprotein (GP) has been associated with the detachment of infected cells and eventually leads to vascular leakage and haemorrhagic fever. Here we report that the membrane-anchored GP is sufficient to induce the detachment of adherent cells. The results show that the detachment induced through either full-length $\mathrm{GP}_{1,2}$ or the subunit $\mathrm{GP}_{2}$ depends on cholesterol and the structure of the transmembrane domain. These data reveal a novel molecular mechanism in which GP regulates Ebola virus assembly and suggest that cholesterol-reducing agents could be useful as therapeutics to counteract GP-mediated cell detachment.

\footnotetext{
${ }^{1}$ Heidelberg University Biochemistry Center (BZH), 69120 Heidelberg, Germany. ${ }^{2}$ Department of Molecular Evolution, Cell and Molecular Biology, Science for Life Laboratory, Uppsala University, 75124 Uppsala, Sweden. ${ }^{3}$ Interdisciplinary Center for Neurosciences, Heidelberg University, Heidelberg 69120, Germany. Correspondence and requests for materials should be addressed to A.M.E. (email: andreas.ernst@yale.edu).
} 
T he current Ebola virus outbreak is the largest and most severe in the history of this virus. Ebola virus poses a threat to thousands of people in West Africa, with outbreaks reported in Guinea, Liberia, Sierra Leone and Nigeria ${ }^{1,2}$. Despite the devastating consequences of Ebola virus infection, the treatment options remain limited and experimental. Recently, the use of cholesterol-reducing agents as an adjuvant therapy to reduce the sepsis-like side effects of Ebola virus disease has been suggested ${ }^{3,4}$. The dysregulation of the immune response and a heavy inflammatory reaction, described as a 'cytokine storm', are induced on EBOV infection 5 . Whether the detachment of infected endothelial cells and the concomitant leakage of the endothelial barrier are important factors in the pathogenesis of Ebola virus disease remains controversial ${ }^{6-11}$. Among other factors, the cytotoxicity of EBOV has been attributed to the envelope glycoprotein (GP) ${ }^{6}$; however, the molecular mechanism underlying the pathogenicity of this virus is unclear. GP is an essential virulence factor that plays a key role in viral entry, membrane fusion, epitope shielding and EBOV assembly ${ }^{12-17}$. Virulence has been attributed not only to the membraneanchored GP but also to the soluble form of this protein, sGP, which results from RNA editing ${ }^{18}$. sGP increases endothelial permeability by acting as an activator of neutrophils and macrophages, which regulates the host immune response ${ }^{19-22}$.

Recently, GP shedding was shown to impact endothelial permeabilization $^{23}$. In addition, the interaction between $\beta 1$-integrin and GP was shown to contribute to the loss of adhesion of GP-expressing cells ${ }^{7,24}$. Furthermore, a role for the $\mathrm{GP}_{2}$ subunit in counteracting interferon-induced antiviral response via the protein tetherin (BST-2) has been proposed ${ }^{25}$. $\mathrm{GP}$ is a type I membrane protein that exhibits high $N$ - and $\mathrm{O}$-glycosylation, and undergoes proteolytical cleavage through furin in the trans-Golgi network, which yields the large amino-terminal $\mathrm{GP}_{1}$ subunit and the small carboxy-terminal $\mathrm{GP}_{2}$ subunit ${ }^{26}$. The $\mathrm{GP}_{2}$ subunit contains a putative fusion peptide and a transmembrane domain (TMD) and is palmitoylated twice on the short cytoplasmic tail ${ }^{27,28}$. Owing to an intramolecular disulfide bond, $\mathrm{GP}_{1}$ and $\mathrm{GP}_{2}$ do not dissociate on furin cleavage ${ }^{29}$. The mature GP forms a trimer that comprises of disulfide-bridged $\mathrm{GP}_{1,2}$ subunits ${ }^{30,31}$. The ectopic expression of GP is sufficient to induce the detachment of adherent cells ${ }^{32}$, and a mucin-like domain within subunit $\mathrm{GP}_{1}$ has been suggested to strongly impact this process ${ }^{6}$. Cell detachment accounts for the loss of the endothelial barrier of infected blood vessels, which putatively leads to vascular leakage and contributes to the high pathogenicity of the virus ${ }^{6,9}$. Ebola virions are filamentous in shape, and the matrix protein VP40 and GP are sufficient to produce protrusions at the plasma membrane of adherent cells $^{33,34}$. The protrusions resulting from VP40 are virus like, whereas the structures resulting from GP alone appear pleiomorphic ${ }^{35,36}$. The combination of VP40 and GP is sufficient to produce filamentous virus-like particles that exhibit the morphology of Ebola virions ${ }^{37,38}$.

Here we report that GP-induced cell detachment might be attributed to the $\mathrm{GP}_{2}$ subunit and that cytotoxicity is strongly impacted through cholesterol and a GXXXA motif in the TMD. Furthermore, we show that the $\mathrm{GP}_{2}$ subunit induces filamentous protrusions at the plasma membrane that also depend on cholesterol and the GXXXA motif, which implies a role for GP in the assembly of the filamentous Ebola virus.

\section{Results}

A mucin-like domain within GP has been attributed to the induction of cell detachment ${ }^{6}$. The isolated $\mathrm{GP}_{2}$ subunit has not been analysed in this context, and notably, the contribution of
$\mathrm{GP}_{2}$ to cell detachment or the production of virus-like filaments was not observed using yellow fluorescent protein (YFP)- $\mathrm{GP}_{2}$ fusions ${ }^{25}$. These results left a possibility that the mucin-like domain, rather than being involved in mediating detachment, acts as a spacer to maintain an appropriate distance between $\mathrm{GP}_{1}$ and $\mathrm{GP}_{2}$ and thereby allow the interaction of $\mathrm{GP}_{2}$ subunits (Fig. 1a). In this case, the deletion of the mucin-like domain then would reduce the relative distance of $\mathrm{GP}_{1}$ to the membrane, causing $\mathrm{GP}_{1}$ to interfere with the oligomerization of $\mathrm{GP}_{2}$. Accordingly, YFP-GP ${ }_{2}$ might not induce cell detachment, as the bulky YFP moiety may have taken the role of $\mathrm{GP}_{1}$ in the $\mathrm{GP}_{1,2}-\Delta$ mucin construct, potentially disturbing $\mathrm{GP}_{2}$ oligomerization and masking the contribution of this protein to cell detachment.

FLAG-GP2 induces protrusions at the plasma membrane. We observed the presence of a seam-like arrangement of Gly and Ala residues with a central G/A/S-XXX-G/A/S motif in the TMD of $\mathrm{GP}_{2}$. These motifs are well-established hubs for TMD-TMD interactions ${ }^{39}$; thus, these motifs likely contribute to the oligomerization of GP. To challenge the hypothesis that TMD-TMD interactions might be disrupted due to the steric hindrance resulting from the presence of a bulky protein (unduly close $\mathrm{GP}_{1}$ in the mucin-like domain deletions or YFP in YFP-GP ${ }_{2}$ ), we designed constructs based on the GP from Ebola Zaire (ZEBOV) by using a small FLAG tag directly fused to the $\mathrm{GP}_{2}$ domain (as depicted in Fig. 1a; Supplementary Table 2). This tag, which contained eight amino acids (with a mass of $\sim 2 \mathrm{kDa}$, including the linker peptide), was not expected to exert strong steric hindrance.

Surprisingly, immunofluorescence and scanning electron microscopy revealed that the transient transfection of HeLa and various other cell lines (Supplementary Fig. 1) with FLAG-GP 2 constructs resulted in the drastic formation of filaments at the plasma membrane (Fig. 1b,c and Fig. 2). The transfection of FLAG-GP 1,2 led to the formation of dot-like structures (Fig. 2a,b, left panel) that likely resemble the previously described $\mathrm{GP}_{1,2}$-induced pleiomorphic structures ${ }^{36}$. The FLAG-GP ${ }_{2}$ induced filaments were, on average, $14.7 \pm 0.44 \mu \mathrm{m}$ in length, and $\sim 50 \mathrm{~nm}$ in diameter (Supplementary Fig. 3a). The observed filament length is consistent with the dimensions observed for the virus-like particles produced through VP40 and $\mathrm{GP}_{1,2}$ (ref. 36). The observed reduction in diameter ( $80 \mathrm{~nm}$ for virions) might reflect the lack of other viral proteins. The filaments exhibited a high extent of peripheral branching, with fine and widespread extensions (Fig. 1b,c). Strikingly, a strong reduction in the volume of the cells was observed concomitant with the production of these filaments and frequently resulted in rod-like cell remnants (Fig. 1b; Supplementary Movies 1-3).

Cytotoxicity of GP is encoded in its $\mathbf{G P}_{2}$ subunit. Next, we analysed the potential induction of HeLa cell detachment through FLAG-GP 2 . Although HEK cells are frequently used to study GP-induced detachment ${ }^{6,32}$, we performed quantitative measurements in HeLa cells, which adhere more strongly and are less prone to detachment than HEK cells. HeLa cells were transfected with either FLAG-GP 2 or FLAG-GP ${ }_{1,2}$ constructs for various times, and the ratio of detached to adherent cells was determined through flow cytometry (Fig. 1d). As a control, we employed plasma membrane-resident (Supplementary Fig. 3f) asialoglycoprotein receptor 1 (ASGR1), which forms trimers similar to Ebola GP. At $36 \mathrm{~h}$ post transfection, $\sim 60 \%$ of the FLAG-GP ${ }_{2}$-transfected cells were detached, whereas ASGR1transfected cells did not exceed 10\% detachment, although the protein levels were higher (Fig. 1d). Importantly, FLAG-GP ${ }_{1,2^{-}}$ transfected cells achieved a similar degree of detachment $(\sim 70 \%$, 
a

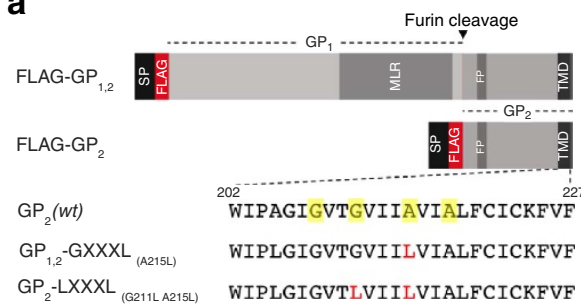

b
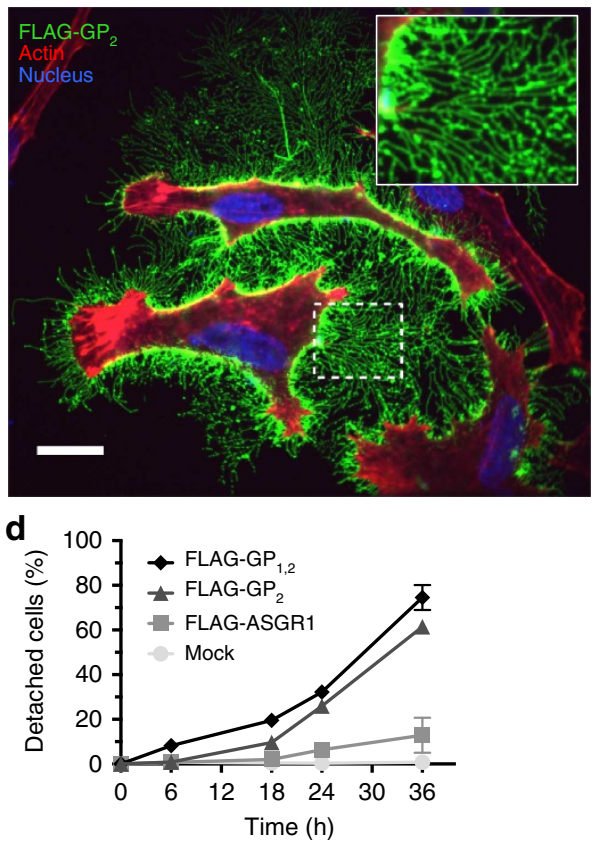

C
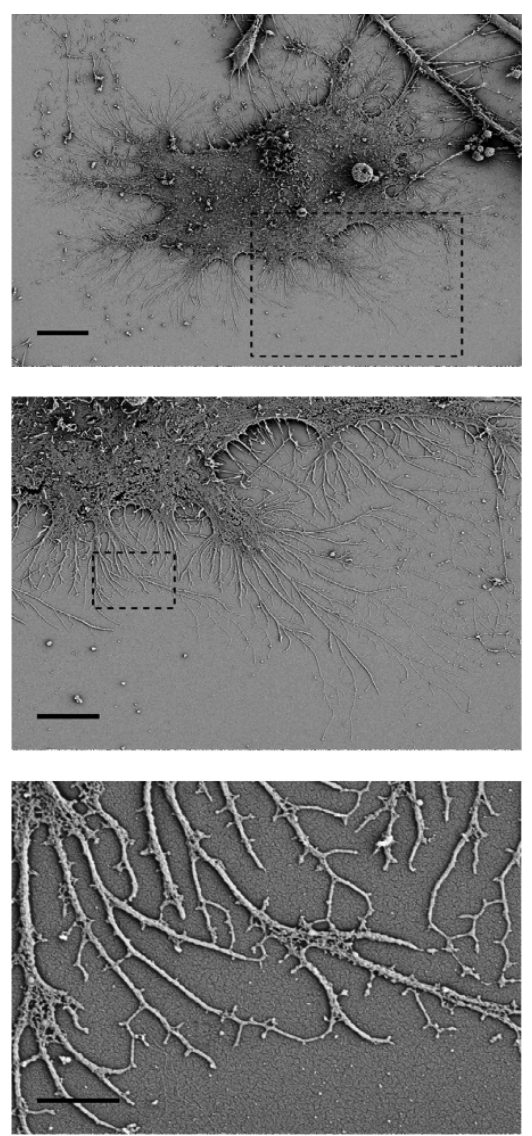

Figure 1 | The $\mathbf{G P}_{\mathbf{2}}$ subunit of Ebola GP leads to filament formation at the plasma membrane of HeLa cells and their detachment. (a) Constructs. All constructs are based on ZEBOV GP. For $\mathrm{GP}_{1,2}$ constructs, a linker-flanked FLAG tag was positioned between the signal sequence and the $\mathrm{GP}_{1}$ subunit. For $\mathrm{GP}_{2}$, the signal sequence of GP was fused to a linker-flanked FLAG tag, followed directly by $\mathrm{GP}_{2}$. GP variants are abbreviated as GP $-\mathrm{LXXXL}$ ( $=\mathrm{FLAG}$ $\mathrm{GP}_{2}-\mathrm{G} 211 \mathrm{LA} 215 \mathrm{~L}$ ), and $\mathrm{GP}_{1,2}-\mathrm{GXXXL}$ ( $=\mathrm{FLAG}-\mathrm{GP}_{1,2}-\mathrm{A} 215 \mathrm{~L}$ ). The respective domains are drawn to scale. SP, signal peptide; FLAG (epitope); MLR, mucin-like region; FP, fusion peptide. Gly and Ala residues seaming the TMD are highlighted (yellow boxes). (b) Immunofluorescence analysis of a HeLa cell transiently transfected with FLAG-GP 2 . Green, FLAG-GP ; red, actin; blue, nucleus. Scale bar, $10 \mu \mathrm{m}$. (c) Scanning electron microscopy of HeLa cells transiently transfected with FLAG-GP 2 at different magnifications. Dashed lines (in $\mathbf{b}, \mathbf{c}$ ): areas of inset. Scale bars indicate $10 \mu \mathrm{m}$ (top), $5 \mu \mathrm{m}$ (middle) and $1 \mu \mathrm{m}$ (bottom). (d) Detachment of HeLa cells transiently transfected with either FLAG-GP, $,-\mathrm{GP}_{2},-$ ASGR1 (as a control) or mock-transfected cells within $36 \mathrm{~h}$. Data points represent the mean $\pm \mathrm{s}$.d. of three independent experiments $(N=3)$. The ratio of adherent to detached cells was determined by flow cytometry. Black diamonds, $\mathrm{GP}_{1,2}$-transfected cells; light black triangles, $\mathrm{GP}_{2}$-transfected cells; dark grey squares, ASGR1-transfected cells; light grey circles, mock-transfected cells.

after $36 \mathrm{~h}$ ), which indicated that the propensity to induce detachment is attributed to the $\mathrm{GP}_{2}$ subunit and not the mucin-like domain within $\mathrm{GP}_{1}$ as previously reported ${ }^{6}$.

A GXXXA motif in the TMD of GP impacts cytotoxicity. Single G/A/S-XXX-G/A/S motifs are able to mediate TMD-TMD interactions ${ }^{39}$. We therefore speculated that the presence of multiple repeats of these motifs, aligned on one side of the TMD of GP (Supplementary Fig. 5b), would enhance GP oligomerization and potentially influence the extent of filament formation and detachment. To this end, we changed the central GXXXA motif in FLAG-GP 2 to LXXXL (as highlighted in Fig. 1a and Supplementary Fig. 5b). This mutant was analysed through immunofluorescence and scanning electron microscopy. Notably, filament formation was strongly inhibited, with the average lengths reduced to $4.7 \pm 0.33 \mu \mathrm{m}$ (Supplementary Fig. 3a). When the propensity of the mutant to confer detachment was analysed, a significant $\sim 50 \%$ reduction was observed compared with wild-type FLAG-GP 2 (Fig. 3b), which suggested that the GXXXA motif contributes to the extent of filament formation and $\mathrm{GP}_{2}$-mediated cell detachment. Strikingly, a single point mutation in full-length FLAG-GP ${ }_{1,2}$, yielding $\mathrm{GP}_{1,2}$-GXXXL, exhibited a drastic reduction of $>50 \%$ in detachment compared with the wild-type construct (Fig. 3a).

On the basis of the immunofluorescence analysis of cells expressing FLAG-GP 2 and co-stained for actin, we observed microfilaments at the basis of the FLAG-GP ${ }_{2}$-induced filaments (Fig. $1 \mathrm{~b}$ and Fig. 2a,b). We therefore incubated the cells with cytochalasin $\mathrm{B}(\mathrm{CB})$, an inhibitor of actin filament polymerization, and observed that $\mathrm{GP}_{2}$-transfected cells no longer exhibited GPinduced filaments, although FLAG-GP 2 was significantly localized to the plasma membrane (Supplementary Fig. 3d), which suggested a role for actin in the observed phenotype, that is, potentially acting as a scaffold for GP-induced filaments.

Cholesterol impacts GP-induced cytotoxicity. Notably, the endomembrane system in FLAG-GP ${ }_{1,2^{-}}$and FLAG-GP $2^{-}$ 

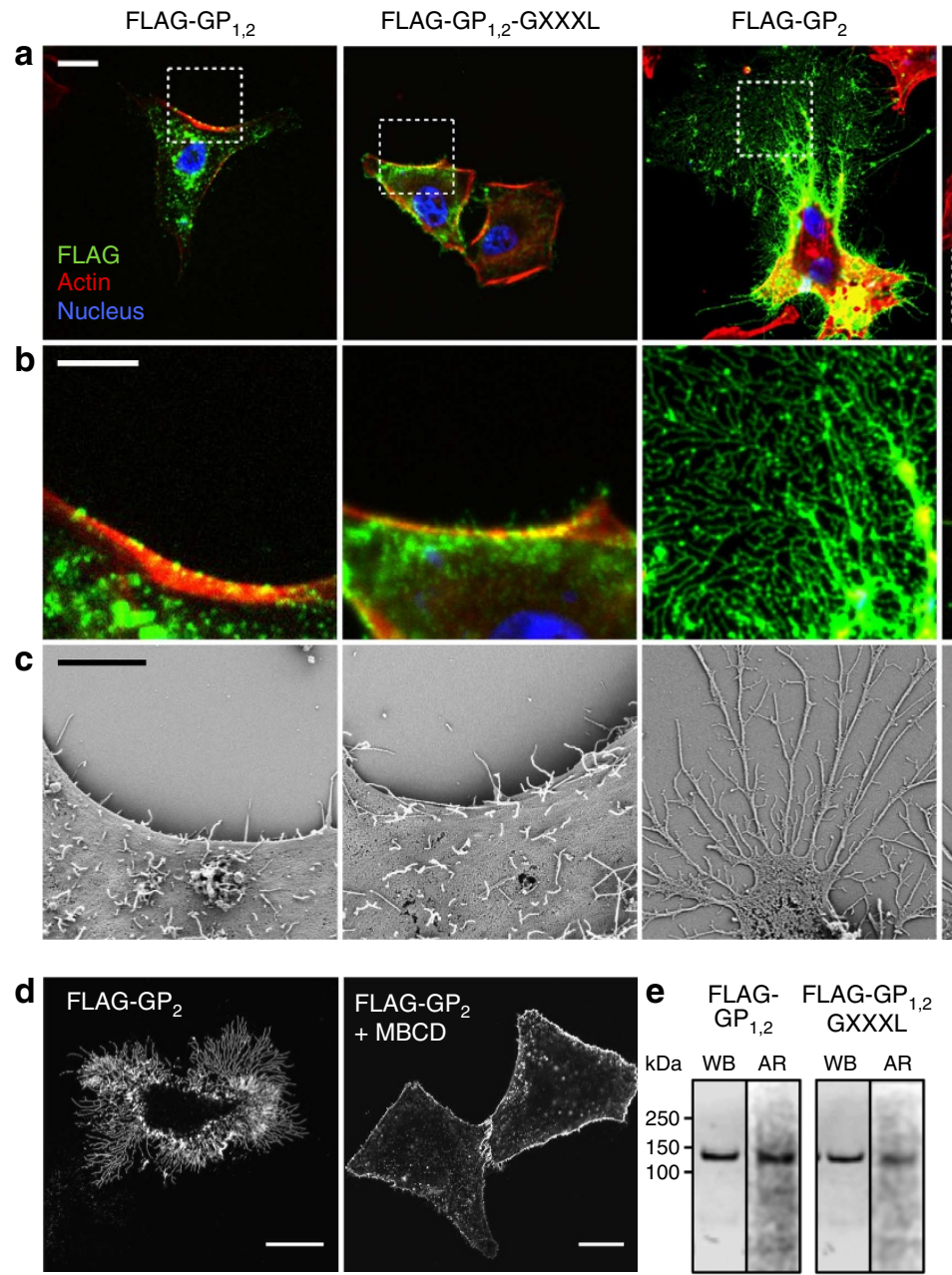

FLAG-GP ${ }_{2}-L X X X L$
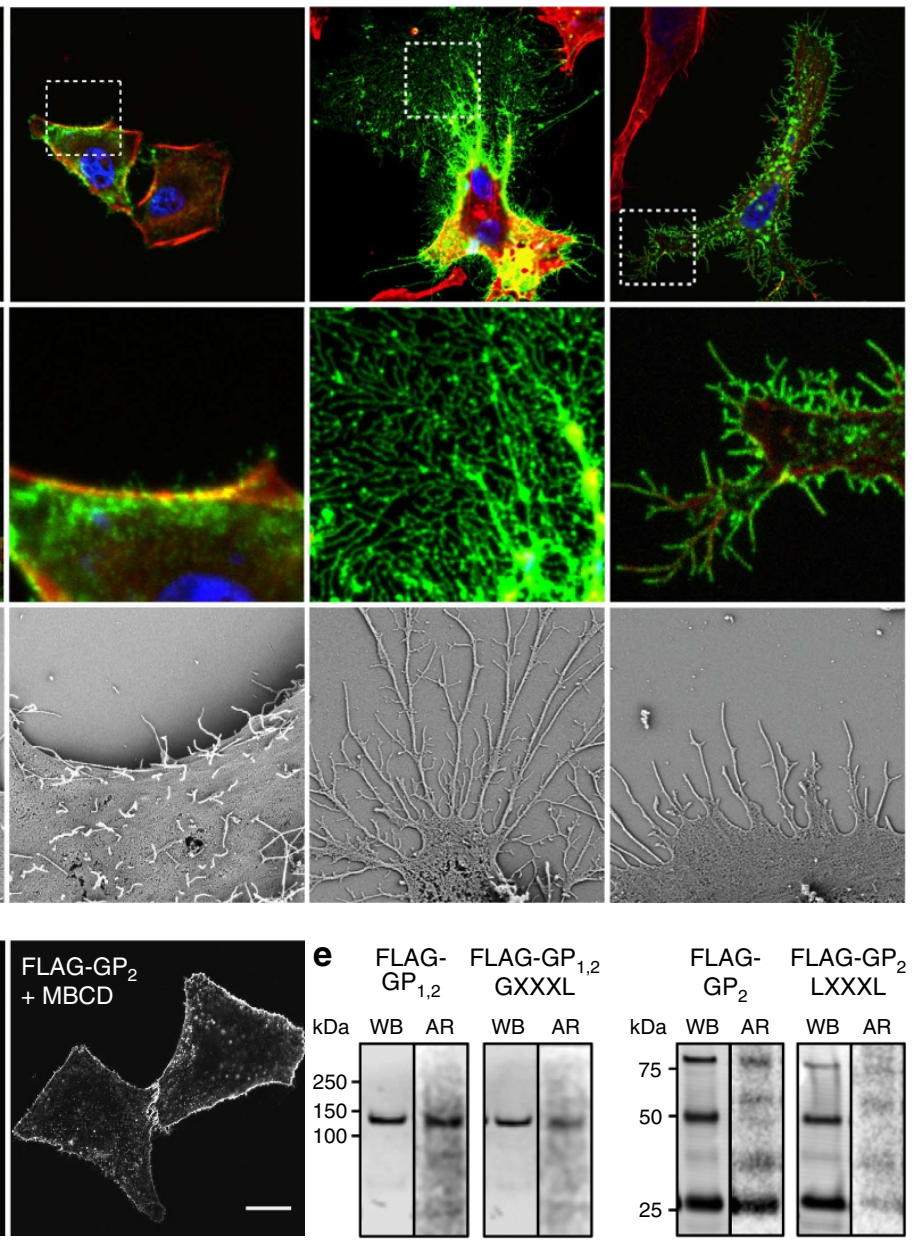

Figure 2 | The TMD of $\mathbf{G P}_{\mathbf{2}}$ affects the morphology of $\mathbf{G P}_{\mathbf{2}}$-induced filaments. (a) HeLa cells were transiently transfected with $\mathrm{FLAG}-\mathrm{GP}_{1,2},-\mathrm{GP}_{1,2}$ - $G X X X \mathrm{~L}_{1}$ $-\mathrm{GP}_{2}$ or $-\mathrm{GP}_{2}-\mathrm{LXXXL}$ for $24 \mathrm{~h}$. The cells were fixed, and FLAG-tagged proteins were visualized by immunofluorescence. Green, $\alpha-F L A G ;$ red, actin; blue, nucleus. Dashed lines, area of inset. Scale bar, $10 \mu \mathrm{m}$. (b) Magnifications of the areas indicated in a. Scale bar, $5 \mu \mathrm{m}$. (c) Scanning electron microscopy images of cells transfected with the indicated constructs. Scale bar, $5 \mu \mathrm{m}$. (d) MBCD abolishes $\mathrm{GP}_{2}$-induced filaments at the plasma membrane. Immunofluorescence analysis of HeLa cells transiently transfected with FLAG-GP ${ }_{2}$ for $24 \mathrm{~h}$, and incubated with a final concentration of $0.5 \mathrm{mM} \mathrm{MBCD} 6 \mathrm{~h}$ post transfection. Scale bar, $20 \mu \mathrm{m}$. (e) GP variants exhibit differences in their ability to bind cholesterol. Photoaffinity labelling of full-length FLAG-GP ${ }_{1,2}$, $-G P_{1,2}-G X X X L,-G P_{2}$ or $-G_{2}-L X X X L$ using tritiated, photolabile cholesterol. HeLa cells were transiently transfected with the indicated constructs for $24 \mathrm{~h}$. After $16 \mathrm{~h}$, tritiated photocholesterol was added. The cells were then ultraviolet irradiated, lysed, subjected to immunoprecipitation against the FLAG epitope and analysed by western blot and digital autoradiography (Supplementary Fig. 8). AR, autoradiography; WB, western blot.

transfected cells appears unaffected (Supplementary Fig. 2a,b). The partitioning of GP into (cholesterol-dependent) detergentresistant membranes ${ }^{40}$ suggested that in addition to the GXXXA motif, the oligomerization of GP might be affected through the increased level of cholesterol at the plasma membrane. A cholesterol gradient exists across the secretory pathway ${ }^{41}$ (low in the endoplasmic reticulum (ER) and high in the plasma membrane), and would hence allow the formation of filaments at the plasma membrane, but not in the endomembrane system.

To analyse the specific interactions of GP with cholesterol, we utilized a well-established photoaffinity-labelling assay $42-45$. Radioactively labelled (tritiated) photoactivatable cholesterol was fed to HeLa cells expressing either FLAG-GP ${ }_{1,2}$, FLAG-GP 2 or their respective variants. At $24 \mathrm{~h}$ post transfection, the cells were irradiated with ultraviolet, thereby crosslinking the photolabile cholesterol analogue to the proteins and lipids in the immediate proximity $(\leq 3 \AA)$. As a control, the equally trimeric and plasma membrane-resident protein ASGR1 was employed. Although ASGR1 exhibited weak labelling despite high expression levels (Supplementary Fig. 3e), both FLAG-GP ${ }_{1,2}$ and
FLAG-GP ${ }_{2}$ were highly and efficiently labelled (Fig. 2e). SDS-resistant oligomers of FLAG-GP ${ }_{2}$ corresponding to dimers and trimers were observed. Strikingly, a strong reduction in photocholesterol labelling was observed for both FLAG-GP $1,2^{-}$ GXXXL and FLAG-GP ${ }_{2}$-LXXXL (Fig. 2e). The reduction in cholesterol labelling of the GXXXA motif point mutants was correlated with a strong decrease in cell detachment of $\sim 50 \%$, respectively (Fig. 3a,b). Therefore, we next analysed the effect of lowering cholesterol in the plasma membrane of FLAG-GP 2 and FLAG-GP ${ }_{1,2}$-transfected cells with regard to filament production and cell detachment. Methyl- $\beta$-cyclodextrin (MBCD) is a wellestablished tool for lowering the cholesterol content in the plasma membranes of mammalian cells ${ }^{46}$. We exposed cells transfected with full-length FLAG-GP 1,2 , FLAG-GP ${ }_{2}$ or variants mutated in the central GXXXA motif to $0.5 \mathrm{mM} \mathrm{MBCD}$ at $6 \mathrm{~h}$ post transfection, which significantly lowered the levels of cholesterol at the time of analysis $24 \mathrm{~h}$ post transfection $(>25 \%$; Supplementary Fig. 4a). Subsequently, we measured the extent of detachment induced through the respective proteins in the presence and absence of MBCD using flow cytometry and 

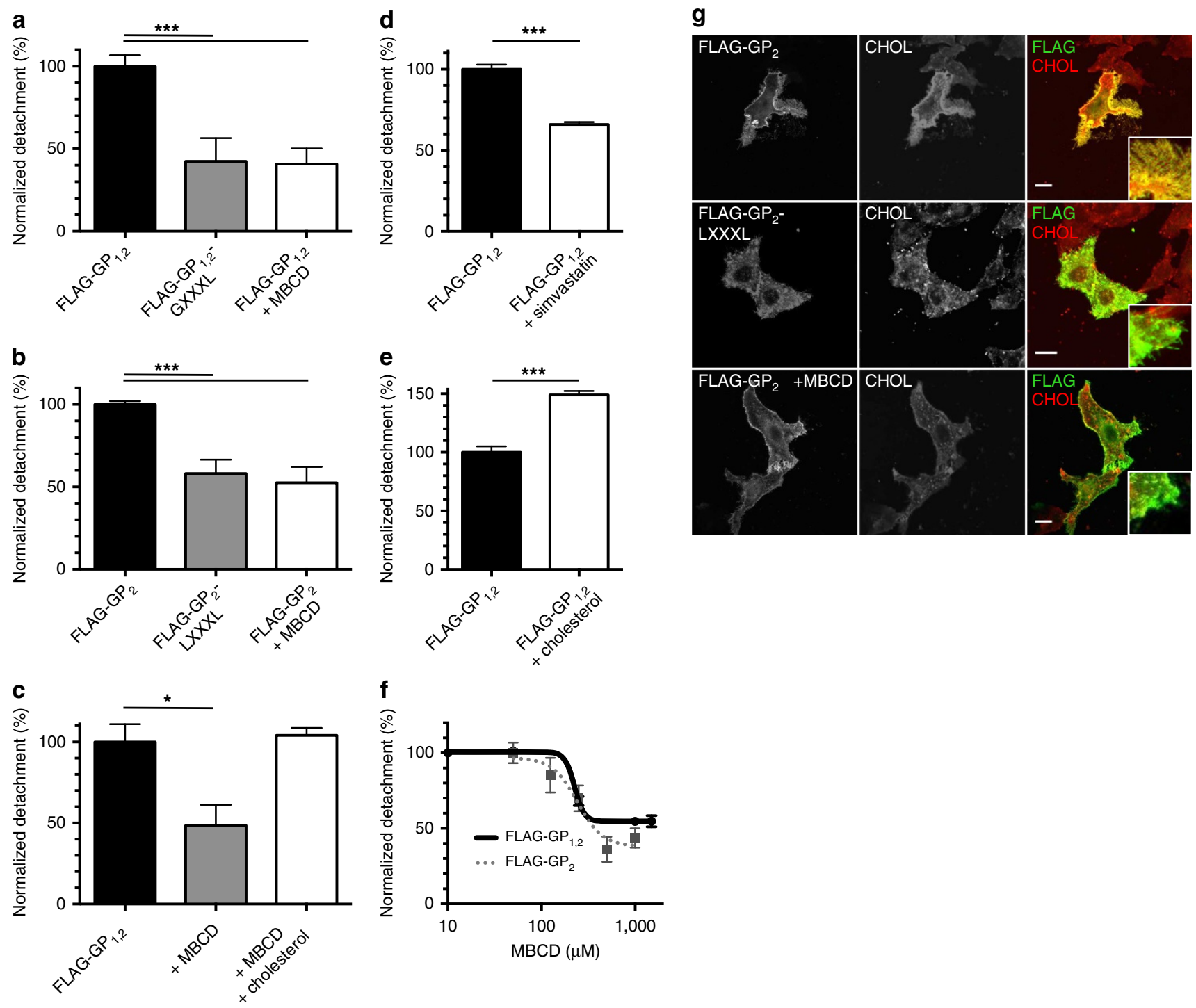

Figure 3 | MBCD suppresses the detachment of cells induced by Ebola GP. (a,b) HeLa cells were transfected with either FLAG-GP 1,2 , its mutant FLAG$\mathrm{GP}_{1,2}-\mathrm{GXXXL}$, FLAG-GP 2 or FLAG-GP $-\mathrm{LXXXL}$ for $24 \mathrm{~h}$. Six hours post transfection, $0.5 \mathrm{mM} \mathrm{MBCD}$ was added. The ratio of adherent to detached cells was determined by flow cytometry. (c) The inhibitory effect of MBCD on GP-induced detachment is overcome by the addition of exogenous cholesterol. Cells transfected with FLAG-GP 1,2 were treated with $5 \mathrm{mM} \mathrm{MBCD}$ for 30 min before transfection. Cholesterol was replenished by incubation with $100 \mu \mathrm{M}$ MBCD-complexed cholesterol for $30 \mathrm{~min}$. (d) Detachment is reduced in statin-treated cells. Cells were cultured in $2 \mu \mathrm{M}$ simvastatin for 4 days. Cells transfected with FLAG-GP 1,2 are compared with cells without statin treatment. (e) Exogenous cholesterol increases GP-induced detachment. Cells transfected with FLAG-GP 1,2 were treated $6 \mathrm{~h}$ post transfection with $100 \mu \mathrm{M} \mathrm{MBCD}$-complexed cholesterol for 30 min. Data points represent the mean \pm s.d. from three independent experiments $(N=3)$. Detachment of ASGR1-transfected cells was subtracted as unspecific detachment. The results of unpaired, two-tailed $t$-tests are given. ${ }^{\star} P<0.05 ;{ }^{\star \star} P<0.01$; ${ }^{\star \star \star} P<0.001$. (f) Titration of MBCD to GP-expressing cells. Cells were transfected with $\mathrm{GP}{ }_{1,2}$ or $\mathrm{GP}_{2}$ and exposed to different concentrations of $\mathrm{MBCD}$ as indicated. The data points represent the mean of three independent experiments $(N=3)$. Error bars represent the s.e.. Best-fit values for a sigmoidal dose response of $\mathrm{GP}_{1,2}$ (black solid line) and $\mathrm{GP}_{2}$ (dashed grey line) are given. The IC 50 of $\mathrm{MBCD}$ mediated inhibition of detachment by $\mathrm{GP}_{1,2}$ was $197.5 \mu \mathrm{M} \pm 25.44$ s.e., and $295.1 \mu \mathrm{M} \pm 98.52$ s.e. for $\mathrm{GP}_{2}$. (g) Cholesterol enriches in $\mathrm{GP}_{2}$-induced plasma membrane protrusions. HeLa cells were transfected with FLAG-GP 2 or FLAG-GP $2-L X X X L$, and treated with $0.5 \mathrm{mM} \mathrm{MBCD} 6 \mathrm{~h}$ post transfection. Cells were fixed and stained with filipin (cholesterol) and anti-FLAG antibodies. Green, FLAG-GP $2 / F L A G-G P_{2}-L X X X L$; red, cholesterol. Scale bar, $20 \mu \mathrm{m}$.

immunofluorescence. Strikingly, MBCD significantly reduced $(>50 \%)$ the level of detachment induced through FLAG-GP ${ }_{1,2}$ and FLAG-GP ${ }_{2}$ constructs (Fig. 3a,b), whereas for FLAG-GP $1,2^{-}$

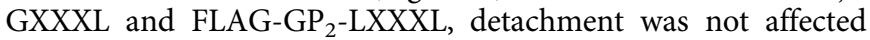
after treatment with MBCD (Supplementary Fig. 3b). Treatment with MBCD alone did not significantly induce the detachment of cells, changes in morphology or interfered with expression of GP (Supplementary Figs 3c, 4c and 7). Accordingly, when we incubated the cells with the statin simvastatin before transfection, a significant reduction in the cholesterol levels was observed (>30\%; Supplementary Fig. 4b), and GP-induced detachment was significantly reduced $\sim 40 \% \quad$ (Fig. $3 \mathrm{~d}$ ). Interestingly, the addition of cholesterol to cells using cholesterol-loaded MBCD strongly increased GP-induced cell detachment (Fig. 3e). Furthermore, the inhibitory effect of MBCD on GP-induced detachment was restored when the cells were incubated with MBCD-complexed cholesterol (Fig. 3c).

Next we expanded the analysis of filoviral $\mathrm{GP}_{2}$ subunits to Marburg virus (MARV) and Lloviu cuevavirus (LLOV), the only two remaining genera of Filoviridae ${ }^{47,48}$. Comparisons of 
the TMDs of the respective $\mathrm{GP}_{2}$ subunits of these viruses (Supplementary Fig. 5a) revealed that EBOV and LLOV share a high extent of sequence identity, including the G/A/S-XXX-G/A/S motif, but that MARV lacks a comparable sequence (Supplementary Fig. 5b). Analogous to EBOV $\mathrm{GP}_{2}$, we examined FLAG-LLOV- and FLAG-MARV- $\mathrm{GP}_{2}$ for the induction of cell detachment and production of plasma membrane protrusions. MARV FLAG-GP $\mathrm{G}_{2}$ induced neither virus-like-filament formation at the plasma membrane, nor significant cell detachment, while the GXXXA motif containing LLOV FLAG-GP 2 triggered cell protrusions and cell detachment comparable to EBOV FLAG-GP 2 , and this effect was susceptible to treatment with MBCD (Supplementary Fig. 5c,d). These data highlight the correlation between the presence of G/A/S-XXX-G/A/S motifs in the TMD of filoviral GP, cell detachment and cholesterol.

Next we employed the cholesterol-specific probe filipin to examine the enrichment of cholesterol in $\mathrm{GP}_{2}$-induced cell protrusions ${ }^{49}$. Although $\mathrm{GP}_{2}$-expressing cells are efficiently labelled at the plasma membrane and its filamentous protrusions, staining of the plasma membrane is strongly reduced in MBCD-treated cells (concomitant with the absence

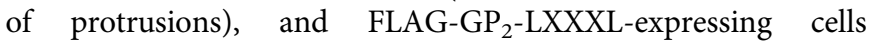
exhibit low filipin co-staining (Fig. 3g). We speculate that the co-aggregation of cholesterol into Ebola virions and the concomitant depletion of plasma membrane cholesterol might also contribute to pathogenicity, as the sequestration of cholesterol would also likely affect the function of cholesterolinteracting receptors and signalling proteins in the plasma membrane, such as the $\mathrm{T}$-cell receptor or $\mathrm{MHC}$ class II molecules ${ }^{50,51}$.

Altogether, these data suggest that the GXXXA motif mediates interactions among GP trimers, generating higher, cholesterolcompetent, GP oligomers. Thus, the mutation of this motif correlates with a loss of MBCD sensitivity and a marked reduction in detachment. The titration of $\mathrm{MBCD}$ revealed a sigmoidal dose response for both $\mathrm{GP}_{1,2}$ and $\mathrm{GP}_{2}$ constructs, with half-maximal inhibition of detachment at similar concentrations (FLAG-GP ${ }_{1,2}$ : $197.5 \mu \mathrm{M} \pm 25.4$ s.e., and FLAG-GP $2: 295.1 \mu \mathrm{M} \pm 98.5$ s.e.; Fig. $3 \mathrm{f})$. Thus, we concluded that the cytotoxicity conferred through GP depends on cholesterol and is additionally influenced by the presence of a GXXXA motif in the TMD. Although these data strongly implicated cholesterol as the major lipid involved in cytotoxicity, we cannot exclude that other lipids were indirectly affected in these experiments. A reduction in the cholesterol levels at the plasma membrane might reflect differences in the composition of specific lipid microdomains targeted through GP, for example, polyunsaturated phospholipids resulted in deformations of the plasma membrane $e^{52}$, and phosphatidylserine levels in the cytoplasmic leaflet might also be affected.

Nonetheless, these data suggest that cholesterol-reducing treatments are potential candidates for therapeutics to counteract the pathogenicity induced through Ebola GP; these treatments could also be employed after infection with Ebola virus as an addition to the established post exposure regimens ${ }^{53-60}$. Cyclodextrins have been patented as antiviral agents for the treatment of infections resulting from various enveloped viruses $^{61}$. Treatment with MBCD is even more promising because the $\mathrm{IC}_{50}$ reported here is $\sim 20$-fold lower than those determined for the herpes, vaccinia, Epstein-Barr and hepatitis $\mathrm{C}$ viruses $^{61}$.

FLAG-GP ${ }_{2}$-induced filaments form by retraction. We next monitored the production of the FLAG-GP ${ }_{2}$-induced filaments through live-cell imaging using a TIRF-DIC (total internal reflection fluorescence-differential interference contrast) microscope set- up. As depicted in Fig. 4c and in Supplementary Movie 1, after $370 \mathrm{~min}$ and within the course of $\sim 70 \mathrm{~min}$, the cells contract with filamentous structures left behind while the cell body retracts, which suggests that the filaments are formed through retraction rather than outgrowth. Moreover, bubbles were observed underneath the cell, and the cells rounded up before eventual detachment, which suggests a correlation between the production of plasma membrane protrusions and cell detachment.

A subset of host proteins exhibits a GP-like TMD arrangement. Subsequently, we analysed the amino-acid sequences of host single-spanning plasma membrane-resident proteins to characterize the seam-like arrangement of Gly and Ala residues present in the TMD of GP. Strikingly, only 26 proteins exhibited more than five Gly, Ala or Ser residues within a seam-like arrangement in the TMD. A total of 14 of these candidates were implicated in cell adhesion or cytoskeleton organization (Fig. 4d, Supplementary Table 1). Among these TMDs are known interactors of GP, such as $\beta 1$-integrin ${ }^{24}$. Nine proteins involved in the immune response (for example, the $\alpha$-chain of HLA class II) were also identified. These findings suggest that $\mathrm{GP}_{1,2}$ might bind to and interfere with these candidates via the GXXXA motif.

\section{Discussion}

As depicted in Fig. 4a, we propose the following model for the formation of GP-induced filaments-at the onset of assembly, GP-TMDs trimerize in a cholesterol-independent manner. During Ebola virus assembly, trimeric GP subunits interact within cholesterol-enriched membrane domains via GXXXAmotifs in the TMDs, generating a lattice-like structure that predominantly contains GP and excludes host proteins (Fig. 4a, centre). When a critical lattice size is formed, this membrane domain collapses around an actin filament that serves as a scaffold for plasma membrane filament formation (Fig. 4b). Matrix protein VP40 participates in this process through oligomerization at the cytoplasmic face of the plasma membrane $^{34,62}$ (Supplementary Fig. 6), further stabilizing the filamentous structures in the viral context and putatively additionally exerting an outward-directed force on the plasma membrane.

In summary, based on the results obtained in the present study, we propose a novel mechanism for Ebola virus assembly at the plasma membrane, based on cholesterol-dependent interactions among GPs, leading to the collapse of large GP aggregates around actin filaments. Rather than through outgrowth, the formation of these filaments reflects the growth of GP aggregates within the plasma membrane and the subsequent wrapping of these aggregates around actin scaffolds (Fig. 4a,b). This mechanism might be closely associated with cell detachment, and suggests two novel drug targets to counter GP-mediated cell detachmentcholesterol, which could be targeted using cholesterol-reducing agents, such as MBCD and statins, and the central GXXXA-motif situated within a seam-like assembly of Gly and Ala residues in the TMD of GP.

\section{Methods}

Reagents and antibodies. $\mathrm{MBCD}$, simvastatin, $\mathrm{CB}$, water-soluble cholesterol, phalloidin-conjugated to Atto 565, Filipin III and EZview red anti-FLAG M2 affinity gel were purchased from Sigma-Aldrich. Prolong Gold Antifade reagent containing 4',6-diamidino-2-phenylindole, 5-hexadecanoylaminofluorescein and WGA conjugated with Alexa 647 were purchased from Life Technologies. Cell dissociation buffer was purchased from Gibco. The following antibodies were purchased from Life Technologies-Alexa Fluor 546 goat anti-mouse, Alexa Fluor 546 goat anti-rabbit, Alexa Fluor 546 donkey anti-sheep, Alexa Fluor 488 goat antirabbit, Alexa Fluor 488 goat anti-mouse. Anti-FLAG mouse and anti-FLAG rabbit were purchased from Sigma. Anti-GM130 mouse was purchased from BD- 

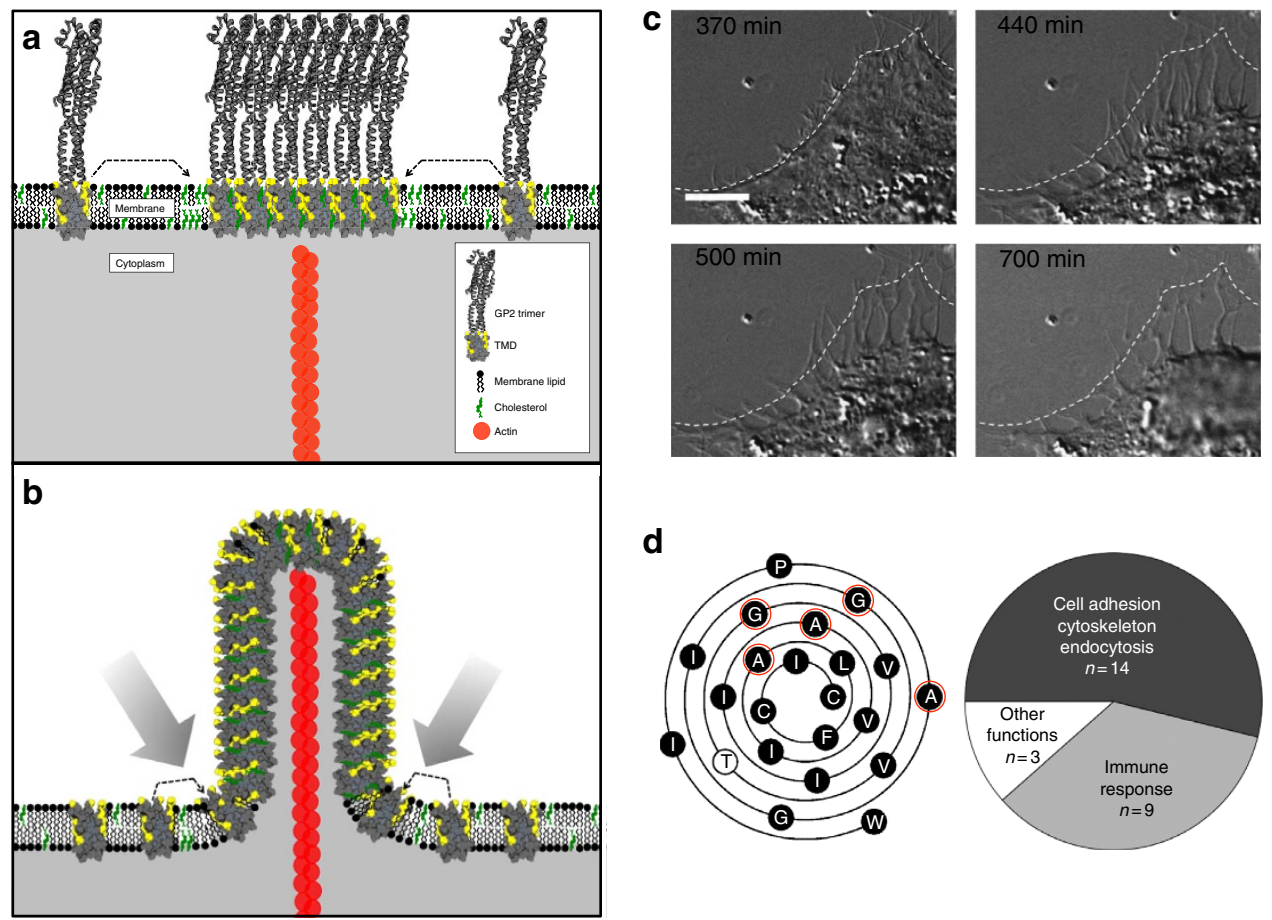

Figure 4 | A novel role for GP in virus assembly at the plasma membrane. (a) Model depicting the proposed initial steps in the formation of $\mathrm{GP}_{2}$-based domains at the plasma membrane. $\mathrm{GP}_{2}$ trimers begin to associate due to elevated levels of cholesterol at the plasma membrane. Interactions among trimers are stabilized via seam-like arranged Gly and Ala residues present in each TMD (highlighted yellow). Black, membrane lipid; green, cholesterol; red, actin; grey/yellow, trimeric TMD of Ebola GP. The TMD was simulated as a solvent-excluded structure using BallView 1.3 and is depicted in grey. The seam-like assembly of glycine and alanine residues is depicted in yellow. Palmitates covalently attached to cysteines 221 and 223 are depicted in blue. The trimeric ectodomain of $\mathrm{GP}_{2}$ (PDB ID: 1EBO) is depicted as grey ribbons. Dashed arrows indicate the addition of $\mathrm{GP}_{2}$ trimers to a growing cholesteroldependent aggregate. (b) The cholesterol-dependent $\mathrm{GP}_{2}$-aggregate reaches a critical mass, and collapses around actin filaments in vicinity to the plasma membrane. Dashed arrows indicate the continuous addition of $\mathrm{GP}_{2}$ trimers to the aggregate, thereby forcing a contraction around the actin-stabilized nascent filament (indicated by bold grey arrows). Here the trimeric ectodomain of $\mathrm{GP}_{2}$ was omitted for clarity. (c) Live-cell differential interference contrast imaging of HeLa cells transfected with FLAG-GP 2 . Cells were imaged for $16 \mathrm{~h}$ at $10 \mathrm{~min}$ intervals, $5 \mathrm{~h}$ post transfection. Dashed line indicates the territory of the cell before the emergence of filament-like structures. Scale bar, $10 \mu \mathrm{m}$. (d) A subset of host membrane proteins exhibit a GP-like TMD architecture. Left, helical wheel representation (Wenxiang diagram ${ }^{67}$ ) of the TMD of ZEBOV GP. Polar residues are depicted as white circles, hydrophobic residues in black. Gly and Ala residues contributing to the seam-like assembly are depicted as black circles with red outlines. Right, mammalian single-spanning membrane proteins that contain $\geq 5$ small side-chained residues (Gly, Ala, Ser) in a $180^{\circ}$ angle, as observed within the TMD of GP. The pie chart depicts the distribution of the annotated functions of the candidates. Candidates with a role in cell adhesion and organization of the cytoskeleton are depicted in dark grey $(n=14)$; light grey, candidates involved in immune response $(n=9)$; white, candidates with other functions $(n=3)$.

Transduction, anti-TGN46 sheep was obtained from Serotec and anti-Calnexin rabbit from Abcam.

Plasmids and constructs. FLAG-tagged cDNA for Ebola $\mathrm{GP}_{2}$ and GP were purchased as synthetic genes from GeneArt (Life Technologies) based on the reverse-translated amino-acid sequences of Uniprot Q05320 (VGP_EBOZM) using the most likely codon usage for $H$. sapiens (Supplementary Table 2). Using EcoRI and NotI sites, the synthetic genes were cloned into $\mathrm{pEGFP-N1}$ vectors, from which EGFP had been removed via EcoRI/NotI digestion. Site-directed mutagenesis was performed using the QuikChange Site-Directed Mutagenesis Kit (Stratagene). FLAG-tagged ASGR1-cDNA was obtained from Origene (clone \# RC205686).

Cell culture and transfection. HeLa cells (DSMZ number: ACC 57) were cultured in $\alpha$-MEM (Applichem) with $10 \%$ fetal calf serum (FCS), $2 \mathrm{mM}$ L-glutamine and $100 \mathrm{U} \mathrm{ml}^{-1}$ penicillin, $100 \mu \mathrm{g} \mathrm{ml}^{-1}$ streptomycin. HEK $293 \mathrm{~T}$ (DSMZ number: ACC 305), COS-7 (DSMZ number: ACC 305) and Vero (ECACC 84113001) cells were cultured in DMEM (Applichem) supplemented with 10\% FCS, 4 mM L-glutamine and $100 \mathrm{U} \mathrm{ml}^{-1}$ penicillin and $100 \mathrm{\mu g} \mathrm{ml}^{-1}$ streptomycin at $5 \% \mathrm{CO}_{2}$ and $37^{\circ} \mathrm{C}$. Transfection was performed using FuGENE HD transfection reagent (Promega) according to the manufacturer's instructions ( $3 \mu \mathrm{g}$ DNA per $9 \mu \mathrm{l}$ FuGENE HD per well of a six-well plate).

HUVEC cell culture and transfection. Human umbilical vein endothelial cells (HUVECs) from single donors (PromoCell) were cultured in Endopan 3 Kit medium (PAN-Biotech) supplemented with $10 \%$ fetal bovine serum, $100 \mathrm{U} \mathrm{ml}^{-1}$ penicillin and $100 \mu \mathrm{g} \mathrm{ml}^{-1}$ streptomycin (Gibco Life Technologies) in a $5 \% \mathrm{CO}_{2}$ humidified incubator at $37^{\circ} \mathrm{C}$. HUVECs were used between passage 1 and 5 . For microscopy studies, HUVECs were plated onto glass coverslips coated with $0.1 \%$ gelatin (from porcine skin; Sigma-Aldrich).

For transfection, the culture medium was removed from a monolayer of $90 \%$ confluent cells. The cells were washed with PBS $(1 \times$; PBS, Sigma-Aldrich) and subsequently trypsinized ( $0.05 \%$ Trypsin-EDTA; Gibco by Life Technologies). A total of $1.5 \times 10^{6}$ cells were resuspended in a final volume of $400 \mu \mathrm{l}$ of electroporation buffer (RPMI-1640-medium supplemented with $10 \%$ fetal bovine serum) and placed in a $0.4 \mathrm{~cm}$ electrode gap cuvette (PEQLAB). $15 \mu \mathrm{g}$ FLAG-GP was mixed with the cell suspension and incubated at $4^{\circ} \mathrm{C}$ for $10 \mathrm{~min}$. Cells were electroporated using an electric pulse generator (BioRad Gene Pulser Xcell) under the following conditions-square wave electric pulse, $250 \mathrm{~V}$ and $40 \mathrm{~ms}$ pulse length. Subsequently, the cells were resuspended in the respective growth media and plated for further assays. After $4 \mathrm{~h}$, the culture medium was replaced with fresh complete growth medium. The images were acquired after $24 \mathrm{~h}$ through confocal microscopy using a Zeiss LSM 510 unit mounted on an Axiovert 200 inverted microscope with a 1.4 Plan-APOCHROMAT $\times 63$ oil objective.

Confocal microscopy. The cells were plated on $35 \mathrm{~mm}$ glass-bottomed dishes (MatTek Corp.) and transfected using FuGENE HD. After $24 \mathrm{~h}$, the cells were washed three times with PBS ( $\mathrm{pH} 7.4$ ) and fixed with $3.6 \%$ paraformaldehyde (SigmaAldrich) for $20 \mathrm{~min}$ on ice. For endomembrane staining, the cells were permeabilized using $0.5 \%(\mathrm{w} / \mathrm{v})$ Triton-X-100 for $5 \mathrm{~min}$ at RT. After washing three times, for blocking, cells were incubated with $1 \%$ bovine serum albumin (BSA; Carl Roth) in PBS for $1 \mathrm{~h}$. Immunofluorescence was performed with a dilution of primary 
antibodies at 1:200 and secondary antibodies at 1:1,000 in 0.5\% BSA in PBS. The primary antibody dilutions were added to the cells for $1 \mathrm{~h}$, followed by washing three times with PBS for $5 \mathrm{~min}$. Secondary antibody dilutions were subsequently added for $30 \mathrm{~min}$. Alexa647-conjugated WGA was used at final concentration of $10 \mu \mathrm{g} \mathrm{ml}^{-1}$ for $20 \mathrm{~min}$, and $10 \mathrm{nmol}$ of Atto565-conjugated phalloidin (Sigma) was added to $1 \mathrm{ml}$ of methanol and incubated with the cells at a dilution of 1:100 in PBS for $30 \mathrm{~min}$. The samples were examined through confocal microscopy using a Zeiss LSM 510 unit mounted on an Axiovert 200 inverted microscope with a 1.3 NA Plan-NEOFLUAR $\times 40$ oil objective, equipped with an argon laser. Image processing was performed using Zen 2011 and ImageJ software.

Quantification of cell detachment using flow cytometry. The cells were plated on 6-well dishes (Corning Inc.) and transfected with the indicated contructs using FuGENE HD. At the indicated timepoints, the dishes were placed on ice. The culture medium containing detached cells was transferred to $1.5 \mathrm{ml}$ tubes and centrifuged for 6 min (10,000 r.p.m.). The supernatant was discarded, and the pellet was resuspended in $200 \mu \mathrm{l}$ serum-free DMEM. The adherent cells were washed once with PBS, and subsequently incubated with $300 \mu$ of EDTA-containing cell dissociation buffer (Gibco) at $37^{\circ} \mathrm{C}$ for $5 \mathrm{~min}$. Subsequently, $300 \mu \mathrm{l}$ of serum-free DMEM was added and the resuspended cells were transfered to $1.5 \mathrm{ml}$ tubes. The ratio of detached versus total cells was quantified using a FACSCalibur flow cytometer (Beckton Dickinson).

Fluorescence stain of membrane cholesterol and quantification. A filipin stock solution was prepared in dimethylsulphoxide at a concentration of $50 \mathrm{mg} \mathrm{ml}^{-1}$. For membrane staining, unpermeabilized paraformaldehyde-fixed cells were incubated with a 1:100 dilution of filipin solution in PBS containing 1\% BSA for 30 min before incubation with the antibodies (primary antibody: 1:200; secondary antibody: 1:1,000) and then subjected to confocal microscopy. To quantify the membrane cholesterol population, six-well plates with adherent cells were treated accordingly, and filipin fluorescence was measured using a MolecularDevices SpectraMax M5 microplate reader at an excitation wavelength of $355 \mathrm{~nm}$ and emission wavelength of $460 \mathrm{~nm}$ (ref. 49).

Treatment of cells with MBCD and CB. A stock solution of $\mathrm{CB}$ was prepared at $5 \mathrm{mg} \mathrm{ml}^{-1}$ in dimethylsulfoxide. To deplete cholesterol and inhibit actin polymerization, $\mathrm{MBCD}$ and $\mathrm{CB}$ were added to the medium at the concentrations indicated $6 \mathrm{~h}$ post transfection and incubated overnight.

Bioinformatics. All proteins annotated as membrane proteins were downloaded from Uniprot ${ }^{63}$. These proteins were homology reduced to $30 \%$ using CD-HIT ${ }^{64}$. To map the TMDs of these proteins, we used DG-pred ${ }^{65}$ with the constraint that a TMD shows a $\Delta$-G score $<0$. To identify putative TMD-TMD interaction interfaces that were enriched in the Gly, Ala and Ser residues, we generated an algorithm that analyses the TMDs from the $z$ axis. On the basis of the assumption of the regular spacing of the residues in these alpha-helical segments, the total number of small side chain-containing residues (Gly, Ala and Ser) and the relative distribution of these residues around the TMD were obtained. Three data sets corresponding to the different subcellular localizations of the membrane proteins (ER, Golgi and plasma membrane) were generated. To evaluate the data, the plasma membrane protein data set was analysed for proteins containing $\geq 5$ residues of Gly, Ala or Ser positioned at an angle of $180^{\circ}$-as observed in the TMD of Ebola GP (Fig. 4d). Falsely annotated entries and those specific to early developmental stages and proteins exclusively present in certain tissues were omitted for clarity.

Depletion and replenishment of cholesterol in the cells. MBCD-complexed cholesterol from Sigma was added to the cells at $6 \mathrm{~h}$ after transfection for $30 \mathrm{~min}$ at a concentration of $100 \mu \mathrm{M}$ in normal growth medium. The cells were washed with PBS and incubated overnight in growth medium. For the rescue experiments, the cells were incubated in $5 \mathrm{mM} \mathrm{MBCD}$ for $60 \mathrm{~min}$ before transfection and washed three times with PBS. At $6 \mathrm{~h}$ after transfection, water-soluble cholesterol was added as indicated.

Treatment of cells with a statin. The cells were cultured in simvastatin at $2 \mu \mathrm{M}$ for 4 days before experiments in normal growth medium. The cells then were subsequently transfected and treated as described above.

Scanning electron microscopy. The cells were plated onto $35 \mathrm{~mm}$ glass-bottomed dishes (MatTek), and transfected for $24 \mathrm{~h}$ with different GP variants. The cells were fixed with $2 \%$ glutaraldehyde in $0.1 \mathrm{M}$ sodium phosphate buffer (Sørensen), pH 7.4 for $2 \mathrm{~h}$, rinsed with buffer and dehydrated with an ascending series of ethanol. The samples were critical point dried using carbon dioxide and the slides were coated with gold $(5 \mathrm{~nm})$. The samples were analysed using a ZEISS ULTRA 55-field emission scanning electron microscope, using the Everhart-Thornley secondary electron detector.
Live-cell imaging. HeLa cells were plated onto 35-mm MatTek glass-bottomed dishes and transfected for $24 \mathrm{~h}$ with $3.3 \mu \mathrm{g}$ FLAG-GP ${ }_{2}$ and $10 \mu \mathrm{l}$ FuGENE HD transfection reagent in complete DMEM medium. After $5 \mathrm{~h}$, the cells were washed with PBS and a HEPES-based imaging medium (Invitrogen). Microscopy was performed on a Nikon TIRF-2 system with Eclipse Ti inverted microscope, using a Nikon Apo-TIRF 1.5 NA $\times 60$ oil objective in differential interference contrast mode with a Hamamatsu 1394 ORCA-ERA camera and an incubation chamber adjusted to $37^{\circ} \mathrm{C}$ and $5 \% \mathrm{CO}_{2}$. Imaging was commenced at $5 \mathrm{~h}$ post transfection, with an acquisition rate of one image per $10 \mathrm{~min}$, for a total duration of $16 \mathrm{~h}$ using NIS-Elements Microscope Imaging Software.

In vivo photoaffinity labelling with cholesterol. FLAG-tagged $\mathrm{GP}_{2}$ and $\mathrm{GP}_{1,2}$ constructs and variants thereof and ASGR1, as a negative control, were probed for protein-cholesterol interaction in vivo. For this purpose, photoactivatable cholesterol was employed for photolabelling experiments as previously described ${ }^{66}$. In brief, HeLa cells were grown in six-well dishes and transfected using FuGENE HD $(1 \mu \mathrm{g}$ DNA $+3 \mu \mathrm{l}$ transfection reagent in $100 \mu \mathrm{l}$ Opti-MEM (Invitrogen) at $\sim 60 \%$ confluency. After $16 \mathrm{~h}$, the cells were labelled with $75 \mu \mathrm{Ci}$ of $\left({ }^{3} \mathrm{H}\right)$-photocholesterol in $3 \mathrm{ml}$ of DMEM supplemented with $10 \%$ delipidated FCS for $8 \mathrm{~h}$. The cells were ultraviolet irradiated for $10 \mathrm{~min}$ on ice and lysed for $1 \mathrm{~h}$ in $100 \mu \mathrm{l}$ lysis buffer (50 mM HEPES-NaOH, pH 7.4, $100 \mathrm{mM} \mathrm{NaCl}, 5 \mathrm{mM}$ EDTA, $1 \%$ Triton-X-100 (v/ v), $0.5 \%$ deoxycholate $(\mathrm{w} / \mathrm{v})$, and protease inhibitor cocktail (cOmplete mini, Roche)). Post-nuclear supernatants were subjected to immunoprecipitation using M2-(anti-FLAG)-affinity gel (Sigma-Aldrich) according to the manufacturer's instructions. The proteins were subsequently eluted in $4 \times$ SDS-polyacrylamide gel electrophoresis sample buffer containing $16 \%$ SDS and subjected to SDSpolyacrylamide gel electrophoresis (10-20\% Tris/Tricine gradient gels, Invitrogen), western blotting and the quantitative immunodetection of FLAG-tagged proteins using a LI-COR infrared imager. Radioactively labelled proteins were detected by digital autoradiography (Beta Imager 2000, Biospace Lab), using acquisition times of $16 \mathrm{~h}$.

\section{References}

1. Check Hayden, E. World struggles to stop Ebola. Nature 512, 355-356 (2014).

2. Baize, S. et al. Emergence of Zaire Ebola Virus Disease in Guinea. N. Engl. J. Med. 371, 1418-1425 (2014).

3. Fedson, D. S. A practical treatment for patients with ebola virus disease. J. Infect. Dis. 211, 661-662 (2014).

4. McElroy, A. K. \& Spiropoulou, C. F. Reply to Fedson. J. Infect. Dis. 211, 662-663 (2015).

5. Feldmann, H. \& Geisbert, T. W. Ebola haemorrhagic fever. Lancet 377, 849-862 (2011).

6. Yang, Z. Y. et al. Identification of the Ebola virus glycoprotein as the main viral determinant of vascular cell cytotoxicity and injury. Nat. Med. 6, 886-889 (2000).

7. Simmons, G., Wool-Lewis, R. J., Baribaud, F., Netter, R. C. \& Bates, P. Ebola virus glycoproteins induce global surface protein down-modulation and loss of cell adherence. J. Virol. 76, 2518-2528 (2002).

8. Geisbert, T. W. et al. Pathogenesis of ebola hemorrhagic fever in primate models: evidence that hemorrhage is not a direct effect of virus-induced cytolysis of endothelial cells. Am. J. Pathol. 163, 2371-2382 (2003).

9. Wahl-Jensen, V. M. et al. Effects of Ebola virus glycoproteins on endothelial cell activation and barrier function. J. Virol. 79, 10442-10450 (2005).

10. Francica, J. R., Matukonis, M. K. \& Bates, P. Requirements for cell rounding and surface protein down-regulation by Ebola virus glycoprotein. Virology 383 , 237-247 (2009).

11. Groseth, A. et al. The Ebola virus glycoprotein contributes to but is not sufficient for virulence in vivo. PLoS Pathog. 8, e1002847 (2012).

12. Carette, J. E. et al. Ebola virus entry requires the cholesterol transporter Niemann-Pick C1. Nature 477, 340-343 (2011).

13. Hunt, C. L., Lennemann, N. J. \& Maury, W. Filovirus entry: a novelty in the viral fusion world. Viruses 4, 258-275 (2012).

14. Reynard, O. et al. Ebolavirus glycoprotein GP masks both its own epitopes and the presence of cellular surface proteins. J. Virol. 83, 9596-9601 (2009).

15. Francica, J. R. et al. Steric shielding of surface epitopes and impaired immune recognition induced by the ebola virus glycoprotein. PLoS Pathog. 6, e1001098 (2010).

16. Hartlieb, B. \& Weissenhorn, W. Filovirus assembly and budding. Virology 344, 64-70 (2006)

17. Jasenosky, L. D. \& Kawaoka, Y. Filovirus budding. Virus Res. 106, 181-188 (2004).

18. Volchkov, V. E. et al. Recovery of infectious Ebola virus from complementary DNA: RNA editing of the GP gene and viral cytotoxicity. Science 291, 1965-1969 (2001).

19. Yang, Z. et al. Distinct cellular interactions of secreted and transmembrane Ebola virus glycoproteins. Science 279, 1034-1037 (1998). 
20. Wahl-Jensen, V. et al. Role of Ebola virus secreted glycoproteins and virus-like particles in activation of human macrophages. J. Virol. 79, 2413-2419 (2005).

21. de La Vega, M.-A., Wong, G., Kobinger, G. P. \& Qiu, X. The multiple roles of sGP in ebola pathogenesis. Viral. Immunol. 28, 3-9 (2015).

22. Mohan, G. S., Li, W., Ye, L., Compans, R. W. \& Yang, C. Antigenic subversion: a novel mechanism of host immune evasion by ebola virus. PLoS Pathog. 8, e1003065 (2012).

23. Escudero-Perez, B., Volchkova, V. A., Dolnik, O., Lawrence, P. \& Volchkov, V. E. Shed GP of ebola virus triggers immune activation and increased vascular permeability. PLoS Pathog. 10, e1004509 (2014).

24. Takada, A. et al. Downregulation of $\beta 1$ integrins by ebola virus glycoprotein: implication for virus entry. Virology 278, 20-26 (2000).

25. Kuhl, A. et al. The Ebola virus glycoprotein and HIV-1 Vpu employ different strategies to counteract the antiviral factor tetherin. J. Infect. Dis. 204 (Suppl 3), S850-S860 (2011)

26. Volchkov, V. E., Feldmann, H., Volchkova, V. A. \& Klenk, H. D. Processing of the Ebola virus glycoprotein by the proprotein convertase furin. Proc. Natl Acad. Sci. USA 95, 5762-5767 (1998).

27. Gallaher, W. R. Similar structural models of the transmembrane proteins of Ebola and avian sarcoma viruses. Cell 85, 477-478 (1996).

28. Ito, H., Watanabe, S., Takada, A. \& Kawaoka, Y. Ebola virus glycoprotein: proteolytic processing, acylation, cell tropism, and detection of neutralizing antibodies. J. Virol. 75, 1576-1580 (2001).

29. Feldmann, H., Volchkov, V. E., Volchkova, V. A., Stroher, U. \& Klenk, H. D. Biosynthesis and role of filoviral glycoproteins. J. Gen. Virol. 82, 2839-2848 (2001).

30. Weissenhorn, W., Carfi, A., Lee, K. H., Skehel, J. J. \& Wiley, D. C. Crystal structure of the Ebola virus membrane fusion subunit, GP2, from the envelope glycoprotein ectodomain. Mol. Cell 2, 605-616 (1998).

31. Sanchez, A. et al. Biochemical analysis of the secreted and virion glycoproteins of Ebola virus. J. Virol. 72, 6442-6447 (1998)

32. Chan, S. Y., Ma, M. C. \& Goldsmith, M. A. Differential induction of cellular detachment by envelope glycoproteins of Marburg and Ebola (Zaire) viruses. J. Gen. Virol. 81, 2155-2159 (2000).

33. Panchal, R. G. et al. In vivo oligomerization and raft localization of Ebola virus protein VP40 during vesicular budding. Proc. Natl Acad. Sci. USA 100, 15936-15941 (2003).

34. Timmins, J. et al. Oligomerization and polymerization of the filovirus matrix protein VP40. Virology 312, 359-368 (2003).

35. Timmins, J., Scianimanico, S., Schoehn, G. \& Weissenhorn, W. Vesicular release of ebola virus matrix protein VP40. Virology 283, 1-6 (2001).

36. Noda, T. et al. Ebola virus VP40 drives the formation of virus-like filamentous particles along with GP. J. Virol. 76, 4855-4865 (2002).

37. Licata, J. M., Johnson, R. F., Han, Z. \& Harty, R. N. Contribution of ebola virus glycoprotein, nucleoprotein, and VP24 to budding of VP40 virus-like particles. J. Virol. 78, 7344-7351 (2004)

38. Johnson, R. F., Bell, P. \& Harty, R. N. Effect of Ebola virus proteins GP, NP and VP35 on VP40 VLP morphology. Virol. J. 3, 31 (2006).

39. Russ, W. P. \& Engelman, D. M. The GxxxG motif: a framework for transmembrane helix-helix association. J. Mol. Biol. 296, 911-919 (2000).

40. Bavari, S. et al. Lipid raft microdomains: a gateway for compartmentalized trafficking of Ebola and Marburg viruses. J. Exp. Med. 195, 593-602 (2002).

41. Colbeau, A., Nachbaur, J. \& Vignais, P. M. Enzymic characterization and lipid composition of rat liver subcellular membranes. Biochim. Biophys. Acta 249 , 462-492 (1971)

42. Eroglu, C., Brugger, B., Wieland, F. \& Sinning, I. Glutamate-binding affinity of Drosophila metabotropic glutamate receptor is modulated by association with lipid rafts. Proc. Natl Acad. Sci. USA 100, 10219-10224 (2003).

43. Umashankar, M. et al. Differential cholesterol binding by class II fusion proteins determines membrane fusion properties. J. Virol. 82, 9245-9253 (2008)

44. Thiele, C., Hannah, M. J., Fahrenholz, F. \& Huttner, W. B. Cholesterol binds to synaptophysin and is required for biogenesis of synaptic vesicles. Nat. Cell Biol. 2, 42-49 (2000).

45. Anishkin, A. \& Kung, C. Stiffened lipid platforms at molecular force foci. Proc. Natl Acad. Sci. USA 110, 4886-4892 (2013).

46. Rodal, S. K. et al. Extraction of cholesterol with methyl-beta-cyclodextrin perturbs formation of clathrin-coated endocytic vesicles. Mol. Biol. Cell 10 961-974 (1999)

47. Negredo, A. et al. Discovery of an ebolavirus-like filovirus in europe. PLoS Pathog. 7, e1002304 (2011).
48. Siegert, R., Shu, H.-L., Slenczka, W., Peters, D. \& Müller, G. Zur Ätiologie einer unbekannten, von Affen ausgegangenen menschlichen Infektionskrankheit. Dtsch. Med. Wochenschr. 92, 2341-2343 (1967).

49. Ginsbach, C. \& Fahimi, H. D. Labeling of cholesterol with filipin in cellular membranes of parenchymatous organs. Histochemistry 86, 241-248 (1987).

50. Anderson, H. A., Hiltbold, E. M. \& Roche, P. A. Concentration of MHC class II molecules in lipid rafts facilitates antigen presentation. Nat. Immunol. 1, 156-162 (2000).

51. Janes, P. W., Ley, S. C., Magee, A. I. \& Kabouridis, P. S. The role of lipid rafts in T cell antigen receptor (TCR) signalling. Semin. Immunol. 12, 23-34 (2000).

52. Pinot, M. et al. Polyunsaturated phospholipids facilitate membrane deformation and fission by endocytic proteins. Science 345, 693-697 (2014).

53. Wong, G., Qiu, X., Olinger, G. G. \& Kobinger, G. P. Post-exposure therapy of filovirus infections. Trends Microbiol. 22, 456-463 (2014).

54. Kilgore, P. E., Grabenstein, J. D., Salim, A. M. \& Rybak, M. Treatment of ebola virus disease. Pharmacotherapy 35, 43-53 (2015).

55. Shurtleff, A. C., Whitehouse, C. A., Cazares, L. H., Ward, M. D. \& Bavari, S. Pre-symptomatic diagnosis and treatment of filovirus diseases. Front. Microbiol. 6, 108 (2015).

56. Warren, T. K. et al. Protection against filovirus diseases by a novel broadspectrum nucleoside analogue BCX4430. Nature 508, 402-405 (2014).

57. Geisbert, T. W. et al. Postexposure protection of non-human primates against a lethal Ebola virus challenge with RNA interference: a proof-of-concept study. Lancet 375, 1896-1905 (2010).

58. Johansen, L. M. et al. FDA-approved selective estrogen receptor modulators inhibit Ebola virus infection. Sci. Transl. Med. 5, 190 ra179 (2013).

59. Qiu, X. et al. Reversion of advanced Ebola virus disease in nonhuman primates with ZMapp. Nature 514, 47-53 (2014).

60. Thi, E. P. et al. Lipid nanoparticle siRNA treatment of Ebola-virus-Makonainfected nonhuman primates. Nature 521, 362-365 (2015).

61. Carlson, R. M., Froberg, M. K., Khan, M. A., Rice, S. A. \& Wallace, K. B. Cyclodextrin compositions and methods of treating viral infections. Patent WO 2003080080 A1 (2003).

62. Adu-Gyamfi, E. et al. The Ebola virus matrix protein penetrates into the plasma membrane: a key step in viral protein 40 (VP40) oligomerization and viral egress. J. Biol. Chem. 288, 5779-5789 (2013).

63. UniProt Consortium. Update on activities at the Universal Protein Resource (UniProt) in 2013. Nucleic Acids Res. 41, D43-D47 (2013).

64. Huang, Y., Niu, B., Gao, Y., Fu, L. \& Li, W. CD-HIT Suite: a web server for clustering and comparing biological sequences. Bioinformatics 26, 680-682 (2010).

65. Hessa, T. et al. Molecular code for transmembrane-helix recognition by the Sec61 translocon. Nature 450, 1026-1030 (2007).

66. Contreras, F. X. et al. Molecular recognition of a single sphingolipid species by a protein's transmembrane domain. Nature 481, 525-529 (2012).

67. Chou, K. C., Zhang, C. T. \& Maggiora, G. M. Disposition of amphiphilic helices in heteropolar environments. Proteins 28, 99-108 (1997).

\section{Acknowledgements}

M.H. was supported by Boehringer Ingelheim Fonds. We thank the Nikon imaging facility Heidelberg for assistance with confocal and live-cell microscopy, and Hilmar Bading for supporting A.H. in performing electron microscopy. pCAGGS-VP40 was a kind gift from Stephan Becker (Marburg).

\section{Author contributions}

A.M.E and M.H. designed and performed the experiments. A.H. performed scanning electron microscopy. P.B. performed the bioinformatics analyses. P.H. and C.R.d.A. performed experiments involving primary cell culture. A.M.E, M.H., B.B. and F.W. wrote the manuscript.

\section{Additional information}

Supplementary Information accompanies this paper at http://www.nature.com/ naturecommunications

Competing financial interests: The authors declare no competing financial interests

Reprints and permission information is available online at http://npg.nature.com/ reprintsandpermissions/

How to cite this article: Hacke, M. et al. Inhibition of Ebola virus glycoprotein-mediated cytotoxicity by targeting its transmembrane domain and cholesterol. Nat. Commun. 6:7688 doi: 10.1038/ncomms8688 (2015). 